\title{
Aprendizaje de las ciencias en la educación básica formal de Bogotá para estudiantes con limitación visual
}

Martínez Andrea', Hurtado Jonathan², Poloche Janyeth³

Categoría 2. Trabajos de investigación

\section{Resumen}

En el documento se muestran los resultados del desarrollo de una investigación cualitativa, (observación no participativa) del proceso enseñanza y aprendizaje de las ciencias; en estudiantes con limitación visual, incluidos en la educación formal de un colegio oficial de Bogotá. Se encontró que la población invidente, posee una adecuación de espacios, que ofrece diferentes herramientas para facilitar el desarrollo intelectual de los estudiantes; sin embargo estas, se encuentran desligadas del proceso de enseñanza de las ciencias en el aula, debido a que los docentes no están capacitados para manejarlas, además cuentan con un sobre cupo de estudiantes. Por lo tanto es muy difícil garantizar un proceso de enseñanza y aprendizaje que transcienda en el estudiante. Se concluyó que la inclusión en la educación, necesita desarrollarse bajo la didáctica multisensorial.

\section{Palabras clave}

Limitación visual, adecuación curricular, didáctica multisensorial de las ciencias, Necesidades Educativas Especiales (NEES)

\section{Objetivos}

\section{General}

Determinar las estrategias de enseñanza y aprendizaje para estudiantes con limitación visual que emplea el colegio Carlos Albán Holguín.

\footnotetext{
UUniversidad Distrital Francisco José de Caldas. Bogotá- Colombia. andrea.martinez1435@gmail.com

2Universidad Distrital Francisco José de Caldas. Bogotá-

Colombia.infanteperdido@hotmail.com

3Universidad Distrital Francisco José de Caldas. Bogotá-

Colombia.jhanyeth15@hotmail.com
} 
Revista Tecné, Episteme y Didaxis: TED. Año 2014, Número Extraordinario. ISSN Impreso: 0121-3814, ISSN web: 2323-0126

Memorias, Sexto Congreso Internacional sobre Formación de Profesores de Ciencias. 08 al 10 de octubre de 2014, Bogotá

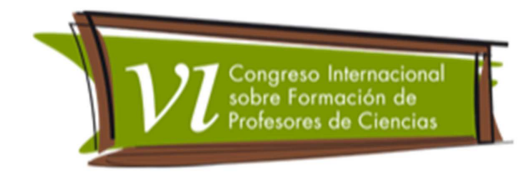

\section{Especificos}

Identificar el enfoque curricular del colegio Carlos Albán para la enseñanza de población con limitación visual.

Generar una propuesta para una buena inclusión de población con limitación visual en el colegio Carlos Albán Holguín.

\section{Marco Teórico}

\section{Currículo}

En cuanto a currículo se han citado diferentes definiciones, dentro de las más sobresalientes se encuentra la de Rule (1973, citado por Sacristán, 1973) donde sostiene que:

El alumno obtiene en la escuela un conjunto de responsabilidades para promover una serie de experiencias de aprendizaje proporcionadas consciente e intencionalmente bajo la supervisión de la escuela, e ideadas y ejecutadas para lograr determinados cambios en los alumnos, o bien experiencias que la escuela utiliza con la finalidad de alcanzar determinados objetivos (Sacristán, 1973, pág. 14)

Sacristán (1973) organiza las definiciones y perspectivas sobre el currículo en cinco ámbitos diferenciados:

- La función social que cumple

- El proyecto o plan educativo pretendido o real

- La expresión formal y material del proyecto educativo

- El campo práctico

- La actividad discursiva académica e investigadora

\section{Adecuación Curricular}

Ésta se entiende como cualquier ajuste o modificación que se realice en varios de los elementos del acto educativo, con el fin de dar respuesta a los alumnos 
Revista Tecné, Episteme y Didaxis: TED. Año 2014, Número Extraordinario. ISSN Impreso: 0121-3814, ISSN web: 2323-0126

Memorias, Sexto Congreso Internacional sobre Formación de Profesores de Ciencias. 08 al 10 de octubre de 2014, Bogotá

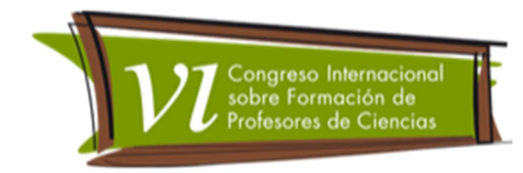

con NEES, pueden ser a nivel de objetivos, contenidos, evaluación, metodología y organización.

\section{Niveles de adecuación Curricular}

Las necesidades educativas especiales, están vinculadas con el contexto educativo por lo tanto las adecuaciones curriculares deben considerarse desde diferentes niveles, los cuales son:

\section{a. Adecuaciones Curriculares de Centro}

Hace referencia a los ajustes que afectan a la escuela en su conjunto, éstas pueden ser a nivel de organización del personal, tales como garantizar profesionales como: logopeda, psicólogos, fisioterapistas, que se consideran necesarios para dar respuesta educativa a los niños con NEES. Pueden hacerse adecuaciones como introducir nuevos métodos de lectura y escritura, con miras a favorecer el proceso de aprendizaje de los niños.

\section{b. Adecuaciones Curriculares de Aula}

Está íntimamente relacionado a los ajustes necesarios específicos para un grupo de niños de un grado determinado, estos ajustes se hacen en las propuestas curriculares que asuma cada aula y por tanto, en las actividades que en las mismas se lleven a cabo, con el fin de cumplir los logros de aprendizaje.

\section{c. Adecuaciones curriculares individuales}

Son todos los cambios que se realizan en las propuestas curriculares para responder a las NEES, de un alumno determinado. Estas se caracterizan porque son ajustes más específicos referidos a modificaciones del currículo y aquellos recursos que no comparten o que el resto de alumnos no necesitan (Carrasco, 2001).

Algunas adecuaciones en este nivel pueden ser:

Adecuaciones en la evaluación: Para este caso en concreto, en el texto "currículo y necesidades educativas especiales" se recomienda utilizar la evaluación de contexto en la práctica educativa.

Adecuación en el cómo enseñar: En este caso se refiere a la variación e introducción de estrategias metodológicas para los alumnos con NEES. 
Revista Tecné, Episteme y Didaxis: TED. Año 2014, Número Extraordinario. ISSN Impreso: 0121-3814, ISSN web: 2323-0126 Memorias, Sexto Congreso Internacional sobre Formación de Profesores de Ciencias. 08 al 10 de octubre de 2014, Bogotá

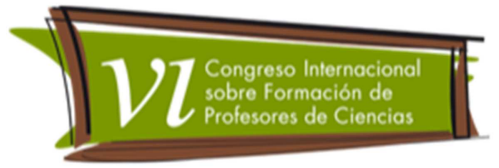

Figura 1. Afectaciones de las adecuaciones curriculares. Ministerio de Educación, Cultura y Deportes. Dirección de Educación Especial (2001).

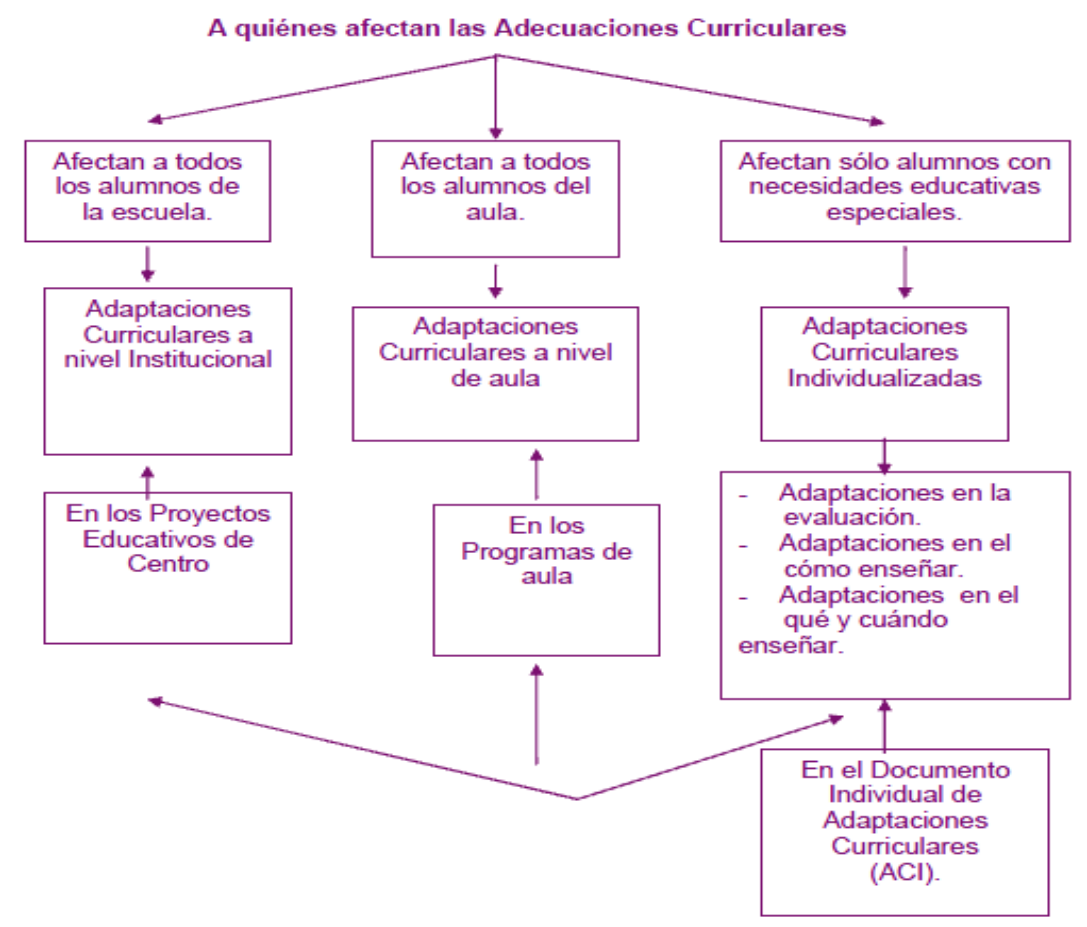

\section{Inclusión docente}

Al presentar el niño como una persona con NEES, se puede eximir la responsabilidad de facilitar las cosas y reforzar las explicaciones de la dificultad de aprendizaje recurriendo al niño o a su familia. Puede demostrarse que los factores escolares influyen mucho más que los de origen familiar en la cantidad de progresos obtenidos por los alumnos (cuatro veces más importante con respecto a la lectura y diez veces más importante en relación con las matemáticas y la escritura), pero a los maestros sigue resultándoles muy difícil prescindir de la idea de que los problemas del aprendizaje residen primordialmente en las características individuales de los niños y en las de sus familias (Cooper,2002).

\section{Alumno}

El alumno es una categoría elaborada por los adultos en el seno de la cultura y de las prácticas sociales, como lo menciona Jimeno Sacristán en su obra "El alumno como invención" en el cual, rastrea con un enfoque interdisciplinar los rasgos más sobresalientes de la trayectoria que han seguido para convertirse en 
Revista Tecné, Episteme y Didaxis: TED. Año 2014, Número Extraordinario. ISSN Impreso: 0121-3814, ISSN web: 2323-0126

Memorias, Sexto Congreso Internacional sobre Formación de Profesores de Ciencias. 08 al 10 de octubre de 2014, Bogotá

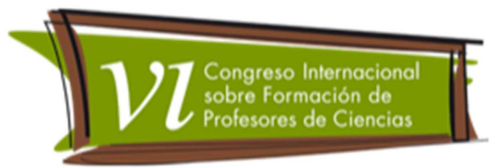

escolares bajo la mirada vigilante, disciplinante, protectora y amorosa (a veces ruda y poco amistosa) de los adultos y más específicamente de los padresy docentes (Sacristán, 2003).

\section{Sujeto con discapacidad visual}

La Organización Mundial de la Salud (OMS) considera que una persona tiene baja visión o es deficiente visual cuando su agudeza visual no sea superior a 1/3 y/o si su campo de visión no supera los 30 grados. Este último es el criterio para ser atendido por parte de los Equipos Específicos de Atención Educativa que la Organización Nacional de Ciegos Españoles (ONCE), en distintos convenios con las Comunidades Autónomas de España, han firmado(Andrade, 2013).

\section{Concepción del sujeto integral}

Un sujeto integral en el proceso de enseñanza aprendizaje está enmarcado en concepciones de tipo constructivista, en el cual, se pretende desarrollar en el estudiante habilidades no sólo del componente conceptual sino también de lo actitudinal, lo axiológico entre otros. Es uno de los aspectos fundamentales planteado dentro del modelo de la reorganización curricular por ciclos, ya que, pretende forjar el desarrollo a escala humana planteada por Max Neef, el cual apunta hacia una práctica pedagógica y participativa; de esta manera se desarrolla en el estudiante aspectos cognitivos, socio afectivos y físico creativos que atañen al ser humano, como se muestra en la figura 2.

Figura 2. Elementos que constituyen la perspectiva de desarrollo humano en la Reorganización curricular por ciclos (SED, 2012).

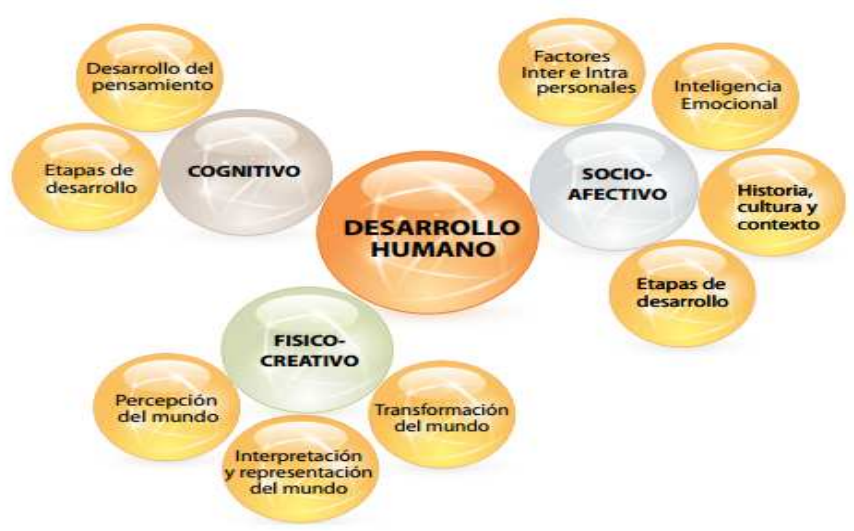

Esquema 2

Elementos que constituye la perspectiva

de desarrollo humano desde la RCC 
Revista Tecné, Episteme y Didaxis: TED. Año 2014, Número Extraordinario. ISSN Impreso: 0121-3814, ISSN web: 2323-0126

Memorias, Sexto Congreso Internacional sobre Formación de Profesores de Ciencias. 08 al 10 de octubre de 2014, Bogotá

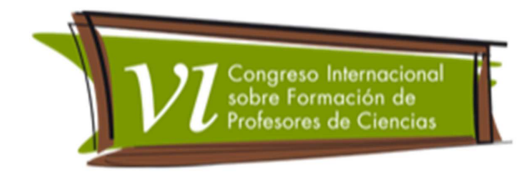

\section{Metodología}

Se realizó una investigación cualitativa (observación no participativa), haciendo uso de la técnica etnográfica, la cual permitió recolectar las evidencias del proceso de enseñanza y aprendizaje de estudiantes con limitación visual de $\mathrm{V}$ ciclo del colegio Carlos Albán Holguín de Bosa. El trabajo de campo y las entrevistas se realizaron con el fin de registrar de manera objetiva la información suministrada; a partir de allí se analizó la información y se construyó una propuesta alternativa para generar una verdadera inclusión en el aula, a través de la didáctica multisensorial de las ciencias.

\section{Resultados}

El colegio Carlos Albán Holguín bajo la dirección de la secretaria de educación de Bogotá, desempeña un papel interesante en la inclusión y atención educativa de los estudiantes con NEES asociadas con multideficit o limitación visual, para lo cual, el colegio posee el departamento de Tiflología. Actualmente presta su servicio a 26 estudiantes certificados, con su respectivo diagnóstico médico, pertenecientes a los 5 ciclos establecidos de acuerdo a la Reorganización curricular.

Las estrategias de enseñanza y aprendizaje que ofrece el colegio para los estudiantes con limitación visual y multideficit en el área de ciencias naturales (Química), están soportadas en un currículo orientado hacia un modelo de enseñanza para la comprensión, donde sobresalen las siguientes adecuaciones curriculares: Contenidos: existe un comité del Departamento de Tiflología que participa en la planeación de actividades de acuerdo a la discapacidad del estudiante; las adaptaciones se elaboran de acuerdo al tema que se está desarrollando en el aula, por lo general se presentan estas modificaciones en los ejes temáticos que se soportan con imágenes visuales como en el caso de teoría atómica; donde sólo se da el concepto de átomo en concreto, para lo cual se trabajan primordialmente textos. El Tiflólogo solo realiza la recomendación al docente, el cual determina si es necesario realizar los respectivos ajustes del contenido.

Dentro de las tareas que se les asignan a los estudiantes se destacan aquellas que requieren el uso de ábaco, de planes caseros, que buscan un vínculo directo para que los padres participen de acuerdo con sus capacidades y habilidades. 
Revista Tecné, Episteme y Didaxis: TED. Año 2014, Número Extraordinario. ISSN Impreso: 0121-3814, ISSN web: 2323-0126 Memorias, Sexto Congreso Internacional sobre Formación de Profesores de Ciencias. 08 al 10 de octubre de 2014, Bogotá

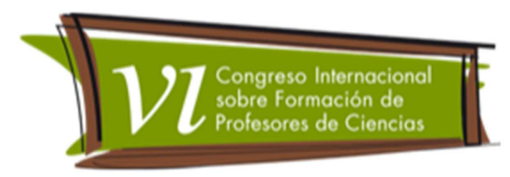

Los elementos que utilizan, en el salón de tiflología, como herramienta para el aprendizaje de los estudiantes con discapacidad visual son:

Un programa lector de pantalla "MexVox" donde el estudiante lee lo que se encuentra en la pantalla a partir de comandos, una impresora braille que es utilizada para los niños de baja y nula visión, un convertidor de texto visual a braille, lupas para niños de baja visión, el ábaco, convertidor de texto a audio, atriles, maquina Perkins y calculadoras. Sin embargo, los docentes que se encargan de impartir los contenidos correspondientes a ciencias no hacen uso de esto, debido a que la gran mayoría utiliza estrategias desarrolladas dentro de su experiencia profesional o solicitan al estudiante que se dirija al aula de tiflología para que él busque la ayuda o las herramientas que necesite para entender los temas; de igual manera, se informó que los docentes pueden solicitar material para llevar al aula, pero ninguno de ellos lo utiliza, lo que implica que el proceso de aprendizaje de las ciencias de los estudiantes sea algo precario, aún sabiendo que dichos estudiantes cuentan con herramientas interesantes que podrían mezclarse con estrategias de aprendizaje desarrollados por el docente titular de las disciplinas de biología, química y física.

Se evidenció en un alto porcentaje de estudiantes, la falta de apoyo y participación de los padres o acudientes en el proceso educativo, ya que, esto se refleja en su bajo rendimiento académico. La dificultad que más sobresale, es la falta de apoyo al docente, debido a que existe en el aula un sobrecupo de estudiantes; entre los que se encuentran los estudiantes con NEES, por lo tanto no hay un proceso de enseñanza y aprendizaje significativo.

A partir del análisis realizado del proceso de enseñanza y aprendizaje en la población invidente y teniendo en cuenta que este presenta ciertas falencias, se empezó a construir una propuesta bajo el lema "La Enseñanza de la ciencia no excluyente" Una Ciencia Para Todos, Fundamentada En La Didáctica Multisensorial (Miquel Albert Soler), la cual se enfatiza en tres importantes aspectos: Educación y detección de necesidades educativas especiales, adecuaciones curriculares y elaboración de materiales o recursos, donde el aprendizaje se desarrolla haciendo uso de los 5 sentidos.

\section{Conclusiones}

El proceso de aprendizaje de población con limitación visual en esté colegio oficial de Bogotá, ha tenido falencias en su desarrollo; debido a que los docentes 
Revista Tecné, Episteme y Didaxis: TED. Año 2014, Número Extraordinario. ISSN Impreso: 0121-3814, ISSN web: 2323-0126 Memorias, Sexto Congreso Internacional sobre Formación de Profesores de Ciencias. 08 al 10 de octubre de 2014, Bogotá

que dictan las disciplinas del saber no se encuentran capacitados para tratar dicha población, así como, la falta de coordinación entre las herramientas y espacios de que dispone dicha población y las estrategias pedagógicas aprendidas por los docentes en su experiencia profesional.

Los estudiantes con NEES no requieren de un intérprete, sino de una figura que vaya más allá, es decir, que apoye los procesos pedagógicos, sociales, culturales; para ello debe navegar en el contexto del estudiante y la didáctica multisensorial como una nueva alternativa de inclusión en la enseñanza de las ciencias.

\section{Referencias bibliográficas}

Andrade, P.M (2013) Alumnos con discapacidad visual. Necesidades y respuesta educativa. Organización Nacional de Clegos españoles. Recuperado de: http://educacion.once.es/appdocumentos/educa/prod/Necesidades\%20y \%20respuesta\%20educativa.pdf

Carrasco, A., María L. (2001). Medidas de Atención a la Diversidad y al Alumnado con Necesidades Educativa Especiales. En: Guía del coordinador. Recuperado de:http://www.nicaraguaeduca.edu.ni/uploads/gcoord_int_pinfan.pdf

Cooper, H. (2002). Didáctica de la historia en la educación infantil y primaria. $2^{\underline{a}}$ edición. Ministerio de Educación cultura y deporte. España: Morata.

Currículo y necesidades educativas especiales. Modulo III. Recuperado de: http://www.nicaraguaeduca.edu.ni/uploads/int_ednino_m3.pdf

Ministeriode Educación, Cultura Y Deportes (2001). Dirección de Educación Especial. Elaboración y Uso de Material Didáctico. En guía del coordinador. Managua, Nicaragua. Recuperado de http://www.nicaraguaeduca.edu.ni/uploads/gcoord_int_pinfan.pdf.

Sacristán, J.G (1973) Aproximación al concepto de currículo. En: Una reflexión sobre la práctica. Madrid: Morata. Recuperado: http://cvonline.uaeh.edu.mx/Cursos/Maestria/MTE/Diseno_d_Proyect_Curric/ Unidad\%201/aproximacion\%20al\%20concepto\%20de\%20curriculum.pdf

Sacristán, J. G (2003) El alumno como invención. España. Editorial Morata. 
Revista Tecné, Episteme y Didaxis: TED. Año 2014, Número Extraordinario. ISSN Impreso: 0121-3814, ISSN web: 2323-0126

Memorias, Sexto Congreso Internacional sobre Formación de Profesores de Ciencias. 08 al 10 de octubre de 2014, Bogotá

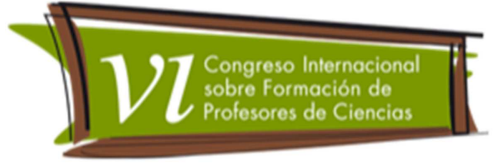

Secretariade Educación Distrital. SED (2012). Reorganización Curricular por ciclos. Referentes conceptuales y metodológicos. Recuperado de: http://www.redacademica.edu.co/archivos/redacademica/colegios/politic as_educativas/ciclos/Cartilla_Reorganizacion_Curricular\%20por_ciclos_2da_E dicion.pdf.

Soler, M (1999). Didáctica multisensorial de las ciencias. Un nuevo método para alumnos ciegos, deficientes visuales y también sin problemas de visión. Editorial Paidós. Buenos Aires - Argentina 